\title{
Membaca Ambiguitas pada Ilustrasi Visual Narasi Pembelajaran Sejarah di Media Sosial.
}

\author{
Andrian Dektisa Hagijanto \\ Prodi DKV, FSD, Universitas Kristen Petra, Jln. Siwalankerto 121, Surabaya 60237, Indonesia \\ andrian@petra.ac.id
}

Sejarah dipelajari melalui berbagai metode menggunakan berbagai media yang berkembang mengikuti perkembangan teknologi. Belajar sejarah tidak lagi membosankan karena dimungkinkan sang pembelajar bebas memilih media yang cocok dan disukainya, termasuk penggunaan berbagai ilustrasi visual. Belajar sejarah menjadi semakin menarik, ketika dilakukan oleh reenactor yang melibatkan penggunaan kostum dan merekayasa impresian sebagaimana serdadu pada jaman perang dahulu. Namun pembelajaran sejarah ternyata menciptakan berbagai narasi yang sarat kepentingan serta menjadi artikulasi dari hidden agenda. Pembelajaran yang juga berpotensi menciptakan kebingungan visual, ketika banyak kreator konten mencampuir-adukan ilustrasi visual secara bebas dan mengabaikan otentisitasnya. Alih-alih sebagai pendongkrak daya tarik yang bebas menggunakan cuplikan dokumentasi sejarah, film komersiil, bahkan dokumentasi drama teatrikal peringatan peperangan sebagai ilustrasi visual pendukung konten tentang pertempuran. Ilustrasi visual itu disusun serampangan yang hanya mengutamakan dramatisasi, mengabaikan otentisitas dan time frame. Ilustrasi visual itu malah menjadi bentuk ambiguitas konten kesejarahan. Paper ini menggunakan metode penelitian kualitatif dengan studi pustaka dan wawancara kemudian analisis visual menggunakan sudut pandang semiologi Barthesian.

Kata kunci : reenactor, visualitas sejarah, ambiguitas.

\section{Reading the Visual Ambiguity of History Narrative in Social Media Content.}

The use of social media as a practical and convenient means of learning resources has brought about conflicting results. As is the case for learning history using footage from historical re-enactment. Re-enactment is an edutainment activity performed by reenactors to respect history by recreating historical events as authentic as possible. Visual documentaries of these performances circulating on the internet have its value as an accessible image for critical and open inquiry of history. However, the nature of its availability is also susceptible to cause misconceptions and false information of historical facts. Content creators that emphasize style over substance, has informally capture and use portions of re-enactment footage to illustrate history narrative that, more than often is used out of its proper context. Images are composed and juxtaposed from various sources, with attention only for dramatization, while disregarding context between images, historical authenticity, and time frame in the process. This article investigates these practices and reveal how, through Barthesian semiology framework, it poses the risk of visual ambiguity in understanding historical re-enactments as contrary to its intended purposes.

Keywords: reenactors, visual of history, ambiguity,

Proses Review : 1 - 20 Mei 2021, Dinyatakan Lolos: 31 Mei 2021 


\section{PENDAHULUAN}

Reenactor adalah sebutan bagi orang yang berpakaian dan mendandani diri dengan replika alat-alat militer sehingga mirip serdadu. Hal itu dilakukan sebagai bagian dari eforia hobby dan aktivitas dalam peringatan pertempuran. Pertempuran yang pernah terjadi dan diperingati sebagai momen bersejarah. Aneka karakter figur dan impresi serdadu ditirukan sebagaimana peristiwa perang yang akan diulang. Tidak hanya berdandan namun juga bermain perang-perangan, sebagaimana improvisasi mereka pada peristiwa pertempuran bersejarah. Aktivitas ini populer dengan istilah reenactment.

Para peniru impresi serdadu tempo dulu dalam drama teatrikal itu merayakan peristiwa perang bersejarah dengan permainan perang-perangan. Reenactor peperangan dilakukan sebagai ungkapan kenangan atas peristiwa perang yang pernah terjadi dalam sejarah mempertahankan kemerdekaan Indonesia. Para reenactor itu beranggapan peperangan yang semestinya peristiwa serius, tragis dan bernuansa kesedihan atas kematian patriotik bunga bangsa pada masa itu diubah menjadi eforia aktivitas berkostum serta fetish kegembiraan impresi yang riang gembira.

Awam sering rancu membedakan reenactor dengan cosplayer karena sama-sama berkostum dan berimpresi. Perbedaan mendasarnya adalah jika reenactor terkait dengan peristiwa sejarah pertempuran maka cosplayer berasal dari figur anime, kartun film dan action figure. Reenactor mengutamakan otentisitas sejarah sebagaimana peristiwa peperangan, sedangkan cosplayer tidak terkait dengan kesejarahan apapun. Aktivitas populer yang dilakukan reenactor dalam memperingati peperangan bersejarah adalah drama teatrikal. Aktivitas ini biasanya menarik perhatian masyarakat karena dilakukan di ruang publik. Dalam aksi itu, reenactor berkesempatan memamerkan kostum dan impresiannya dihadapan publik, berbaur dengan publik dan diajak berswafoto. Unggahan hasil foto sering ditemukan di media sosial milik reenactor dan kelompok-kelompoknya atau dokumentasi dari penonton. Biasanya ditambahi dengan komentar kebanggaan yang sifatnya narsistik dan lucu. Foto-foto dan video unggahan pada peristiwa reenactment juga beredar di media-media sosial termasuk di kanal Youtube. Tidak sedikit foto dan video dokumentasi aktivitas reenactor dipakai sebagai konten pembelajaran sejarah peperangan. Dokumentasi yang dihasilkan reenactor dan masyarakat umum menjadi sumber belajar. Ini menciptakan fenomena kontestasi pembelajaran sejarah melalui media sosial. Hal itu menjadi cara pembelajaran sejarah yang berbeda dengan media konvensional. Belajar sejarah menjadi kegairahan baru dan wacana kreatif terkait cara dan media yang digunakan. Sosok-sosok serdadu dan peralatan perang replika menjadi sumber belajar sejarah yang berbeda. Sebagai media alternatif yang bertebaran bebas di kanal atau akun-akun media sosial yang mudah diakses dan menyesuaikan kebiasaan media si pengakses.

Sejarah adalah subjek pembelajaran yang dalam perspektif lama dianggap kurang menarik, penuh hafalan dan cenderung bersifat sinkronik. Itu terstigma dari sifat metode dan jenis sumber belajar yang klasik dan konvensional. Reenactor ingin mengubah hal tersebut melalui impresian sehingga menjadi bersifat atraktif, interaktif, sangat menarik jauh dari kesan kuno atau membosankan. Belajar sejarah menggunakan 'pintu masuk' impresian dan outfit yang terlihat gagah akan menciptakan daya tarik visual. Sumber belajar sejarah juga menjadi lebih mengasyikkan jika menggunakan visualitas berbentuk foto dan film dokumentasi. Selain menarik karena faktor visual, belajar sejarah jadi lebih menyenangkan karena memungkinkan pembelajar beropini dan berinteraksi langsung.

Ilustrasi visual yang dipakai sebagai daya tarik dalam konten-konten pembelajaran sejarah di Youtube juga tidak lepas dari kiprah reenactor. Dokumentasi aktivitas mereka juga dipakai sebagai 'bumbu penyedap' konten pembelajaran sejarah tentang Perang Kemerdekaan 19451950. Reenactor sebagai bagian dari kelompok penyuka sejarah dan impresian serdadu mempunyai fokus perhatian dan pengetahuan secara otentik dokumentatif pada peralatan dan karakteristik peperangan. Oleh karenanya reenactor menjadi kelompok kritis yang aktif menyuarakan opininya terhadap konten-konten kesejarahan yang dianggap 'melenceng' dari pakem. Walaupun disisi lain, aktivitas para reenactor dalam drama teatrikal peperangan yang terdokumentasikan itu berpeluang menjadi objekobjek visual yang dimanfaatkan juga oleh pihak lain. Kreator konten mengunggah konten sejarah dengan memanfaatkan aktivitas reenactor. Konten dibuat secara serampangan mengabaikan kualitas metodologis. Kontenkonten bertema sejarah peperangan dibuat asal-asalan dengan mencomot aneka dokumentasi termasuk impresian dan drama teatrikal peringatan peperangan sebagai ilustrasi visualnya. Konten sejarah bukan lagi menjadi sumber belajar sejarah namun hanya sekedar unggahan asal-asalan yang non sejarah.

Aktivitas reenactor dalam relasi penciptaan media baru sumber belajar sejarah, memicu trend eforia berkostum dan impresian yang memvisualkan epos-epos peperangan. Hal itu dimaknai peneliti sebagai kegembiraan yang memunculkan upaya alternatif yang berorientasi pada ekspose sejarah populer sebelumnya. Namun di sisi lain, memunculkan juga varian-varian konten kesejarahan yang lebih mengedepankan daya tarik visualisasi ketimbang otentisitas dan objektivitasnya. Artinya, muncul bentukbentuk konten sejarah yang hanya sekedar polesan ilustrasi visual tanpa kedalaman bahkan mengabaikan kebenaran sejarah. Hal ini seakan kontras dengan kebiasaan klasik bangsa ini, dimana kisah-kisah tentang heroik-patriotisme dan nasionalisme lisan disampaikan turun temurun, tersimpan dalam angan dan memunculkan 

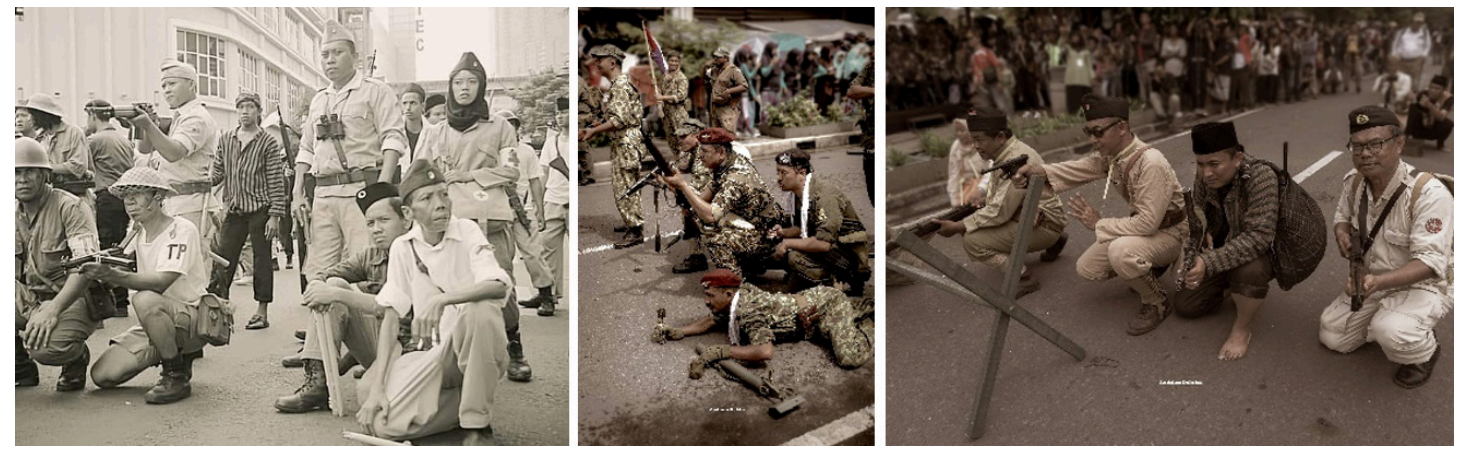

Gambar 1. Para reenactor dengan impresi pejuang dan tentara Belanda pada salah satu drama teatrikal peringatan Serangan Oemoem 1949, yang dilakukan 1 Maret 2020. (Sumber: foto koleksi Andrian, 2020)

imaji-imaji kolektif yang terlestarikan turun temurun, misalnya kisah si Pitung yang diingat sebagai pendekar kebal yang melawan Belanda namun dikhianati temannya dan akhirnya tewas ketika Belanda berhasil mengambil jimatnya. Kisah epos kolektif semacam itu menciptakan imaji-imaji personal dibenak yang terdekonstruksi oleh ilustrasi visual kontemporer. Ilustrasi visual yang tidak lagi menyediakan alternatif bentuk visual lain. Imaji tentang si Pitung yang beraneka bentuk tergantung orang yang mengimajinasikan itu, sirna tergantikan oleh ilustrasi visual yang dilihat melalui media sosial. Media sumber belajar sejarah di media sosialpun berpeluang menjadi konten yang sarat artikulasi. Oleh karenanya dalam penelitian ini, terdapat dugaan bahwa belajar sejarah perang dengan cara dan metode demikian membuka terjadinya kebingungan sejarah yang berpeluang tidak tercapainya tujuan pembelajaran.

\section{METODE PENELITIAN}

Penelitian ini adalah kualitatif menggunakan kajian deskriptif. Teknik pengumpulan data menggunakan studi pustaka dan observasi. Pencarian data dilakukan dengan memanfaatkan aplikasi Whatsapp, Facebook dan kontenkonten di Youtube sebagai wujud kepatuhan penjarakan sosial pada masa pandemi Covid 19.

Analisis data menggunakan cara semiologi Barthesian, yakni mendudukan objek material konten program tayangan "Indonesia Indonesia Dalam Peristiwa" milik salah satu kanal TVOne yang diunggah ke kanal Youtube sebagai aspek denotatif. Peneliti melakukan tangkapan gambar pada unggahan Youtube itu untuk memudahkan analisis. Teori budaya visual menjadi objek formal yang berfungsi sebagai aspek konotatif. Pemaknaan atas relasi kedua objek itu menjadi argumentasi atau mitos. Dugaan awal adalah budaya visual yang bekerja pada objek material menciptakan narasi kesejarahan yang ambivalensi. Model cara penelitian seperti itu menjadi salah satu alternatif yang memungkinkan dilakukan sebagai salah satu bentuk studi visual pada keilmuan Desain Komunikasi Visual.

\section{ANALISIS DAN INTEPRETASI DATA.}

\section{Budaya visual dalam eforia pembentukan makna pada kostum serdadu.}

Media-media sosial berbasis internet yang mengekspose pembelajaran sejarah pada saat ini nampaknya lebih mengedepankanvisualisasidaripadapaparanverbal.Apalagi didukung aktivitas reenactor yang menciptakan visualisasi peringatan pertempuran lalu mendokumentasikannya. Penggunaan kostum dan impresian yang mengedepankan otentisitas, bersifat visualistis dan interaktif menjadi sumber belajar yang menarik. Reenactor menciptakan konten-konten pembelajaran sejarah melalui unggahan aktivitas reenactment di media sosial. Unggahan yang mengedepankan visualisasi dan otentisitas, namun unggahan itu berpeluang dicopy, dicuplik bagi kepentingan penciptaan konten-konten lain. Konten otentik yang berubah menjadi non otentik ketika faktor kontekstualitasnya diabaikan. Otentisitas yang semestinya menjadi faktor penting yang mendasari suatu ekspose sejarah terabaikan oleh pertimbangan raihan respon netizen yang melihat unggahan itu. Dalam bahasa populer media sosial meraih jumlah like sebanyak mungkin.

Pada media pembelajaran sejarah kontemporer, daya tarik visual menjadi orientasi utama dibanding data tarik verbalnya. Visualitas dipakai sebagai objek yang mendukung terbentuknya makna atas hal-hal yang hendak disampaikan. Hal ini selaras dengan pendapat Mirzoeff yang mengutip pendapat Dikovitskaya, (2006) bahwa budaya visual adalah konstruksi budaya yang menempatkan teks visual sebagai sentral atas terbentuknya makna dalam konteks budaya tertentu, serta menjadi sentral bagi terbentuknya pemahaman atas media visual (visual media) baik bagi individu maupun kelompok masyarakat (Mirzoeff, 2009:8).

Objek kajian budaya visual adalah terkaitpengalaman visual sehari-hari, dari foto sampai video rekam, dari pameran seni sampai kegiatan masyarakat (Mirzoeff, 2005:7). Dalam komunikasi visual dipahami sebagai tanda atau 
teks yang mempunyai makna, dan tidak boleh dilepaskan dari konteks budaya di mana objek visual tersebut berada. Karena diaplikasikan di berbagai hal, maka penyajian atau bentuk artifisialnya menjadi wacana/cara pandang, bahkan memungkinkan dikaji secara ilmiah (Rose,2003:3 dan Mirzoeff,2009:8). Budaya visual sebagai objek lapangan penelitian visual juga memungkinkan wacana-wacana perbedaan sosial dijabarkan. Oleh karenanya penelitian yang mengadopsi perspektif budaya visual percaya bahwa budaya visual merupakan konstruk-konstruk pengalaman visual kehidupan sehari-hari sebagaimana ditunjukkan dalam media, representasi dan seni-seni visual menurut Mitchell dalam Dikovitskaya (2006).

Sisi kolaboratif antara Budaya Visual dengan keilmuan atau sudut pandang formal lain terlihat dari relasi konteksnya, misalnya dengan antropologi, sejarah seni, atau terkait dengan kepentingan tertentu yang menjadi hidden message nya. Misalnya ekonomi, kapitalisme dan kajian-kajian tentang posmodern. Konteks ini lah yang dipahami Mierzoff turut memperkaya dan memperluas bidang kajian budaya visual. (Dikovitskaya, 2006:18). Dalam tataran praksisnya, budaya visual menjadi praktik atas kesenangan estetis, nilai-nilai spiritual yang terkait dengan bentuk-bentuk khusus dari produksi dan adopsi keperbedaan kondisi historis dan rejim kekuasaan (hal.20). Dalam cara pandang kontemporer form follows fun sebagaimana pemikiran Lyotard, Jean Boudrillard, Derrida, atau Julia Kristeva. Beroperasi menjadi parodi, kitchs, camps dan skizofrenia, budaya visual diaplikasikan dalam fokus kajian seni tidak lagi berkaitan dengan aspek budaya tinggi yang eksklusif. Tetapi juga aspek ide, kebiasaan, kepercayaan, dan perilaku sehari-hari komunitas tertentu sebagai bagian dari kebiasaan dan 'budaya' kelompok komunitas itu (Rampley, 2005). Aplikasi kontemporer yang berwujud visual dipakai untuk berkomunikasi visual melekat pada makna, tujuan sekaligus peluang untuk menjadikannya objek artikulasi pemerhati teks visual. Dengan kata lain, dalam kontekstualitasnya artefak berpotensi menjadi objek pemaknaan ini menjadi apa yang Stuart Hall dalam Sturken \& Wrights (2004) katakan sebagai ikut pembentukan penciptaan kesan (making sense) yang memudahkan terjadinya pertukaran makna (exchange meanings). Oleh karenanya budaya visual tidak hanya terlihat namun juga juga terekspresikan (utterable). Keith Moxey dan Dikovitskaya $(2006,26)$ menawarkan pendekatan semiotik untuk menentukan cara di mana karya seni secara aktif bekerja untuk menghasilkan makna sekaligus untuk menentukan nilai-nilai dalam masyarakat. Menurut Hagijanto (2017) membaca narasi kesejarahan yang ditawarkan oleh reenactor dengan memakai pintu masuk kostum dan impresian serdadu perang kemerdekaan, nampaknya menjadi pemaknaan bahwa sebagai salah satu wujud aplikasi budaya visual, pakaian tidak hanya sekedar pemuas kebutuhan primer dan salah satu wujud ekspresi seni tata busana, namun juga alat untuk menciptakan kesan (sense) dan makna (meanings), sebagaimana pendapat
Umberto Eco (dalam Barnard, 1996, vi) yang mengatakan 'I speak trough my cloth'.

Jargon itu sebagai penegas bahwa busana adalah juga alat komunikasi, karena menjalankan fungsi retoris memainkan peran membentuk aturan (rules of the game), menjadi semacam ungkapan ritual yang menjalankan tanggung jawab budaya. Pakaian juga berfungsi sebagai alat menyampaikan pesan artefaktual non verbal dan pembentukan identitas kolektif, sekaligus solidaritas suatu kelompok karena didalamnya terdapat kode-kode busana (Nordholt, 1997:1, dalam Barnard 2006: x).

Kostum dan impresi serdadu menjadi pakaian yang mengedepankan fungsi konotatif (dalam istilah Saussure sebagai 'parole') menjadi cara berbicara, cara berperilaku, cara mendekorasi dan ungkapan gaya hidup, atau sebagai 'the age of fashion' menurut Featherstone, Hepworth \& Turner, dalam 'The Body: Social Process and Cultural Theory' (p.311). Barnard (1996:12). Pakaian menjadi komoditas paling fethis yang diproduksi serta dikonsumsi masyarakat kapitalisme. Fungsinya sebagai fashion lebih dominan dibanding sekedar pakaian. Menjadi alat paling signifikan bagi manusia dalam mengonstruksi, mengalami, dan memahami relasi sosialnya.

\section{Program TV 'Indonesia Dalam Peristiwa' dalam kanal Youtube.}

Salah satu fenomena yang menarik sebagai objek material dalam tulisan ini adalah unggahan Youtube yang berasal dari program televisi berjudul 'Indonesia Dalam Peristiwa' dari TV One. Program ini memaparkan kondisi Indonesia setelah Proklamasi tahun 1945. Bangsa Indonesia yang berjuang mempertahankan kemerdekaan 1945 baik melalui jalur diplomasi dan pertempuran bersenjata. Masa yang populer disebut Perang Kemerdekaan Indonesia tahun 1945-1950.

Dalamprogrampembelajaran sejarahituselainmemaparkan narasi verbal dengan teknik male voice over, terdapat juga ilustrasi visual yang diambil dari dokumentasi foto dan film yang terkait peristiwa bersejarah itu. Terdapat juga paparan dan analisa dari tokoh peristiwa atau ahli sejarah berkompeten dari institusi akademik. Ilustrasi visualnya muncul berupa cuplikan atau penggabungan foto atau film (moving image) yang menggambarkan pasukan, alat-alat perang seperti artileri, kapal perang, kendaraan perang atau pesawat tempur. Adegan peperangan yang berbentuk foto dan film dokumentasi sejarah juga ditampilkan dominan.

Visualitaskonten itidakseluruhnyaberasaldaridokumentasi asli peristiwa bersejarah itu, namun banyak yang berasal dari potongan adegan film perang populer. Cuplikan filmfilm seperti Janur Kuning (Alam Surawidjaja, 1979), Kereta Api Terakhir (Mochtar Soemodimedjo, 1981), Serangan Fajar (Arifin C Noer, 1982), Surabaya 45 (Imam Tantowi, 1990), sering dipakai. Selain adegan baku tembak 
yang dicuplik dari film komersial tersebut, visualitas figurfigur sejarah juga mengambil sosok pemain film yang memerankan tokoh itu. Misalnya Kaharuddin Syah yang memerankan sosok Soeharto, atau Dedi Sutomo yang menjadi Jendral Soedirman.

Pada konten di media Youtube yang mengulang tayangan TVOne berjudul "Indonesia Dalam Peristiwa" edisi Januari 2021 tentang Perjalanan Perjanjian Renville ke Konferensi Meja Bundar terdapat contoh modus tersebut. Konten itu berisi paparan ahli sejarah dan akademisi sejarah yang menerangkan peristiwa perjanjian Renville sampai ke Perjanjian Meja Bundar. Ada visualisasi adegan pertempuran yang dicuplik dari karakteristik perang 1945 sebagaimana tangkapan gambar dari kanal Youtube sebagai Gambar 2, dibawah ini:
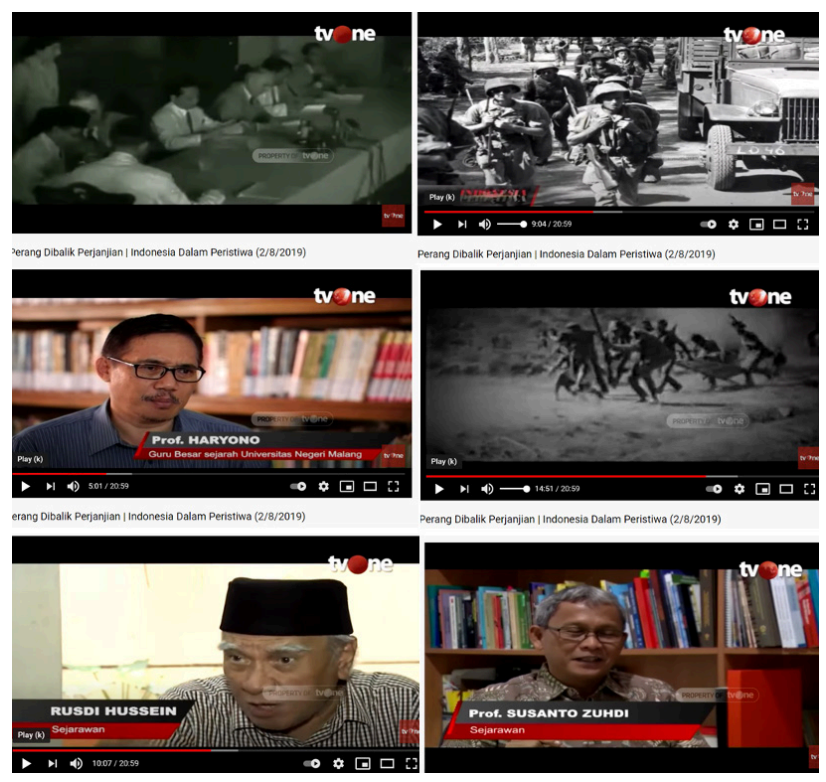

Gambar 2. Visual percampuran antara dokumentasi sejarah, narator papara ahli sejarah dan dokumentasi karakteristik perang tahun 1945 (Imam Tantowi, 1990).

(Sumber: tangkapan gambar unggahan Youtube tahun 2019, diunduh pada 2021)

Gambar 2 adalah tangkapan gambar dari video unggahan di Youtube yang berasal dari tayangan berjudul "Perang Dibalik Perjanjian Indonesia" pada salah satu episode "Indonesia Dalam Peristiwa" milik kanal TV One. Dalam konten berdurasi 60 menit, yang juga diunggah ke kanal Youtube itu memperlihatkan bahasan tentang peperangan yang terjadi dibalik perjanjian-perjanjian yang dilakukan oleh Indonesia dengan Belanda setelah Proklamasi. Konten berisi paparan pendapat ahli (narasi verbal) yang diselingi dokumentasi film yang menggambarkan adegan perundingan, para tokoh yang terlibat perundingan, serta pertempuran. Episode tayangan itu menjadi tayangan sejarah tentang perundingan Linggarjati yang dikhianati Belanda dengan ilustrasi pertempuran-pertempuran skala kecil yang terjadi akibat pengingkaran Belanda itu. Ilustrasi visual dalam unggahan di Youtube memapaparkan beberapa dokumentasi sejarah (gambar atas) berupa kontingen perundingan dari pihak Indonesia, kemudian pendaratan pasukan Brigade Marinir KNIL di Pasir Putih, Situbondo pada 1947. Pada gambar tengah kiri memperlihatkan Prof Haryono sejarawan dari Universitas Negeri Malang sedang memaparkan analisisnya. Kemudian bagian kanan adalah cuplikan adegan pertempuran. Gambar paling bawah adalah paparan dari dua sejarawan (Rusdi Hussein dan Profesor Susanto Zuhdi) yang menjelaskan dan menganalisa tentang sebab akibat yang terjadi seputar Perjanjian Linggarjati.

Sekilas tidak ada yang aneh dalam tayangan program itu, namun jika diamati lebih lanjut terdapat percampuran visual yang melibatkan adegan pendaratan pasukan KNIL dan adegan pertempuran yang berasal dari karakteristik perang Surabaya 1945. Itu memberikan kesan bahwa adegan pertempuran dalam narasi perundingan seolah menjadi bagian yang dianggap tidak signifikan. Adegan pertempuran hanya menjadi penarik pandang ketika sejarawan sedang berbicara. Visualisasi sejarawan hanya mempertontonkan wajah, sehingga menjadi monoton. Dalam beberapa detik membuat penonton bosan. Maka ilustrasi visual peperangan ditampilkan untuk mengatasi kebosanan visual. Audio tetap menampilkan suara sejarawan yang tengah mengemukakan analisanya. Walaupun sekedar penarik pandang yang dimaknai 'kalah berwibawa' dibanding narasi sang ahli, visualitas perang bukan berarti sekedar imaji sepele bisa diambil dari sumber-sumber yang tidak berhubungan dengan kontekstualitas narasi. Penciptaan visualitas peperangan semestinya bukan menjadi ilustrasi yang bebas dan berkesan suka-suka.

Visualitas peperangan dalam konten yang menjadi alternatif sumber belajar sejarah seyogianya dipertimbangkan secara serius dengan menyesuaikan otentisitas materi. Sumber belajar sejarah menjadi teks yang mempertimbangkan relevansi dan pendukung konteks sebagaimana subjek dan waktu terjadinya peristiwa. Konten tentang Perjanjian Linggarjati semestinya menampilkan narasi visual dan verbal yang saling berhubungan. Kedua narasi harus menjadi konten yang berorientasi pada peristiwa Perjanjian. Kalaupun menampilkan ahli dan sejarawan saat ini masih dapat diterima dan dianggap wajar. Menjadi ironi jika paparan sejarawan dan para ahli dalam tayangan itu sebagai sesuatu yang faktual namun visualitas pertempuran yang dipakai sebagai ilustrasi justeru tidak mendukung hal tersebut. Ilustrasi visual yang berfungsi sebagai penarik pandang dan bumbu penyedap justeru bertolak belakang dengan narasi sejarah.

Penggambaran adegan peperangan yang diambil dari dokumentasi visual perang Surabaya yang terjadi tahun 1945 menjadi ilustrasi visual peperangan berbeda konteksnya. Visualitas peperangan dalam konten itu 

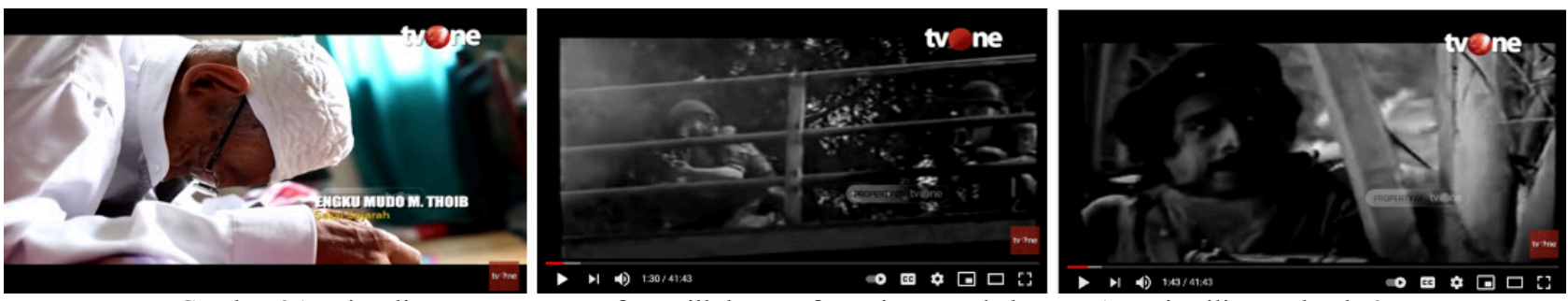

Gambar 3A. Visualitas pencampuran figur riil dengan figur tiruan pada konten Agresi Militer Belanda 2,

Program Indonesia dalam Sejarah oleh TVOne yang diunggah ke kanal Youtube (Sumber: tangkapan gambar Youtube, 2021)
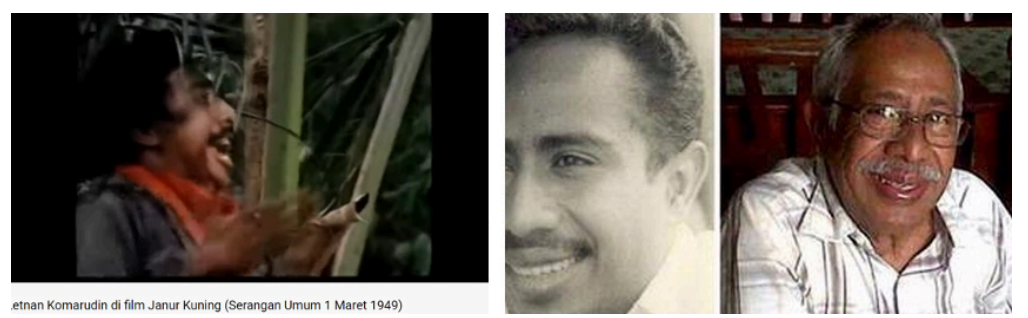

Gambar 3b. Visualisasi figur Letnan Komarudin menggunakan figur artis Amak Baldjun, pemeran sosok letnan Komarudin dalam film Janur Kuning (Alam Surawidjaja, 1979). (Sumber: Youtube, 2021)

dimaknai sebagai kekacauan visual yang terjadi disekitar peristiwa Perjanjian Linggarjati. Reenactor yang memang mengkhususkan perhatian pada kostum dan impresian serdadu dengan mudah mendeteksi kejanggalan visualitas dari karakteristik kostum dan arsenal yang nampak. Senjata dan kostum pada tampilan adegan pertempuran terlihat khas sebagaimana era tahun 1945. Menjadi nampak sangat 'kedaluwarsa' jika digunakan untuk penggambaran situasional peristiwa Linggarjati yang terjadi tahun 1947. Kostum yang digunakan masih mengesankan pertempuran rakyat jelata yang menjadi ciri khas peperangan melawan Inggris yang terjadi seusai mendarat di Indonesia. Tampak sekali dalam karakteristik pejuang yang menjadi cikal bakal pasukan TNI. Sementara karakteristik visual pejuang kemerdekaan tahun 1947 mulai memperlihatkan kostum dan identitas batalyon kesatuan tempur.

Gambar 3A adalah tangkapan gambar dari tayangan tentang Agresi Militer Belanda Kedua. Dalam tayangan itu terdapat ilustrasi yang menggunakan visualisasi tokoh saksi sejarah peperangan yakni Tengku Mudo M Thoib dan Letnan Komarudin. Kedua figur ini betul ada dan terdokumentasikan dalam sejarah. Tengku Mudo sebagai representasi ulama kharismatik dan Letnan Komarudin sebagai serdadu gagah berani. Dalam tayangan itu, visualisasi Tengku Mudo menggunakan sosok dirinya sendiri yang sedang sujud sambil berbicara terbata-bata karena faktor usia sangat renta, sedangkan Komarudin mengambil sosok Amak Baldjun, salah satu artis yang melambung popularitasnya karena berperan sebagai Letnan Komarudin dalam film Janur Kuning (Alam Surawidjaja, 1979) lengkap dengan cuplikan aksinya pada scene penyerbuan ke pos militer Belanda yang salah tanggal. Lihat Gambar 3A dan 3B.

Scene yang memperlihatkan sosok Letnan Komarudin tidak diambil dari dokumentasi sejarah yang memperlihatkan foto-foto riil sosok sang letnan, walaupun ada beberapa dokumentasi tentang sosok riil Komarudin, namun kreator konten justeru memilih menggunakan penggambaran dari figur Amak Baldjun. Hal ini dapat dimaknai ada maksud tertentu misalnya terkait popularitas atau karena sebab lain. Uniknya ketika scene dari cuplikan film itu digunakan sebagai ilustrasi visual konten, kreator mengubah tampilannya menjadi hitam putih sehingga menjadi seakan-akan mengesankan dokumentasi sejarah yang otentik bukan cuplikan dari film komersiil.

Hal itu mengingatkan pada trik propaganda ala Orde Baru dengan penciptaan imaji-imaji sosok hero-patriotik menggunakan figur-figur menawan. Artis-artis dengan rekam jejak baik bukan sosok kontroversial menjadi bagian dari artikulasi tentang pahlawan yang idel, figur yang baik, bertanggung jawab, rela berkorban jiwa raga namun berhati lembut, menawan. Figur yang bertahan dan mampu mengatasi kondisi keterpaksaan, rela dan ikhlas meninggalkan keluarga atau mengorbankan kehidupan normalnya, termasuk menyedekahkan harta bendanya untuk pembiayaan perjuangan. Sosok-sosok ini melekat dalam representasi Kaharuddin Syah atau Dedi Soetomo yang memerankan Overste Soeharto dan Jenderal Soedirman dalam film Janur Kuning. Figur ibu Soedirman yang sukarela menyerahkan perhiasan satusatunya miliknya untuk dipakai mendukung perjuangan suaminya. Suatu dramatisasi bagi konstruksi epos-epos kepahlawanan dan artikulasi suri tauladan sosok-sosok pahlawan kemerdekaan Indonesia. Suatu representasi konstruk keteladanan dan sikap patriotik khas gaya Orde Baru.

Perjalanan hidup Letnan Komarudin seusai pertempuran Serangan Oemoem penuh dinamika. Serdadu itu dianggap tidak lagi mendukung citra figur pahlawan yang bersih dan jauh dari kehidupan kontroversi sebagaimana cara 


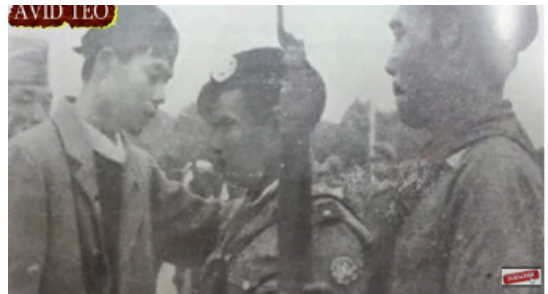

ISAH LETNAN KOMARUDIN PAHLAWAN YANG AKHIIRNYA MENJADI...

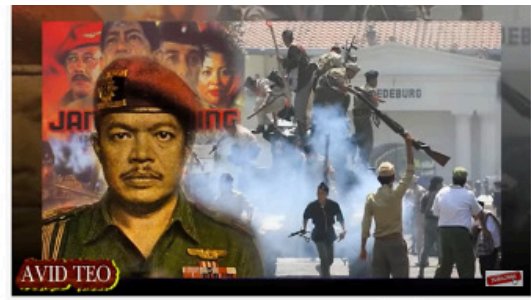

KISAH LETNAN KOMARUDIN PAHLAWAN YANG AKHIRNYA ME $\mathrm{SOr}$,

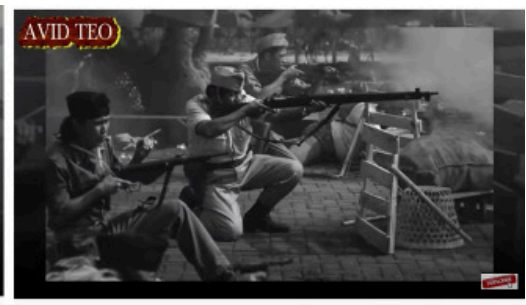

KISAH LETNAN KOMARUDIN PAHLAWAN YANG AKHIRNYA MENJADI.

Gambar 4. Visual percampuran ilustrasi sosok asli Letnan Komarudin (gambar kiri atas dan tengah) dan adegan peperangan yang diambil dari aksi teatrikan Reenactor dalam peringatan Serangan Oemoem tahun 2015

(Sumber tangkapoan gambar dari Youtube, 2021)

pandang rejim itu. Kehidupan karier Letnan Komarudin yang dianggap tidak sehaluan membuatnya kehilangan kualifikasi. Pahlawan adalah narasi yang harus terlihat superior dan afirmatif objektifitasnya. Rejim ikut menentukan pilihan atas figur-figur dalam kepentingan penciptaan imaji-imaji tentang pahlawan. Pahlawan yang populer ternyata tidak sejalan dengan kebijakan Kekuasaan, namun the show must go on. Diakui atau tidak, kenyataannya Letnan Komarudin adalah sang hero. Mitos sebagai serdadu pemberani yang kebal peluru diakui mantan para anak buahnya. Sejarah tentang keberanian dalam bertempur di Serangan Oemoem 1 Maret 1949 menjadi kisah populer yang akan diingat dan dilestarikan oleh orang-orang terdekatnya. Cerita heroik itu mengisi ruang imajiner dan menyebar, orang-orang menjadikannya sebagai konstruk imaji kepahlawanan yang sejajar dengan kontruk-konstruk imaji kepahlawanan Overste Soeharto. Padahal dua figur yang berkontestasi dalam imaji sebagai hero yang saling kontradiktif atau bertolak belakang. Namun figur Letnan diperlukan untuk melegasikan figur Letnan Kolonel.

Oleh karenanya artikulasi Letnan Komarudin pada figur Amak Baldjun merupakan upaya pencitraan tentang keteladanan pahlawan untuk membangun kembali imaji positif pada Letnan Komarudin. Suatu konstruk yang digunakan untuk mendukung imaji-imaji kepahlawanan dan eksistensi Soeharto sebagai tokoh penting dalam Serangan Oemoem 1 Maret 1949. Letnan Komarudin sebagai anak buah yang berani dan kebal peluru ikut menciptakan kualifikasi pada konstruk-konstruk tentang kehebatan sang komandan.

Artinya, Letnan Komarudin yang dilekatkan pada sosok Amak Baldjun yang populer dengan teriakan "ayo maju!....ayo tembak aku!" dalam scene janur Kuning menjadi upaya penciptaan duplikasi retrospektif atas kisah riil kehidupan sang letnan dari Ambon. Menciptakan pengulangan kembali dengan tujuan mencari sisi positif dari sesuatu yang dianggap tidak positif. Sang letnan kontroversial itu ditinjau ulang namun dengan visualitas berbeda, letnan kebal peluru itu terdisposisi oleh aktor film, karena ia adalah preman yang berseberangan dengan sang komandan. Sosok kehidupan sang letnan yang tetap mempertahankan idealismenya adalah narasi yang disembunyikan. Letnan yang akhirnya membangkang perintah komandannya yang menjadi presiden itu dan memilih tetap bertahan di Yogyakarta sampai akhir hayatnya, ia bahkan minta dikuburkan di pemakaman umum di daerah Sleman padahal layak dianggap pahlawan. Kisah Letnan Komarudin adalah segurat getir epos kepahlawanan dalam kisah keberhasilan pertempuran 1 Maret 1949. Sayangnya pembuat konten di Youtube memilih narasi itu sebagai salah satu bangunan konstruk tentang figur Letnan Komarudin dalam epos sejarah tentang Agresi Militer Belanda Kedua. Suatu narasi yang membuatnya kehilangan otentisitas sejarah, sebab menyandingkan antara sosok Tengku Mudo M Thoib dengan 'sosok palsu' hasil impresian Letnan Komarudin. Hal itu dimaknai sebagai bentuk objektivitas yang tidak 'seimbang'. 'Modus' serupa muncul juga dalam unggahan-unggahan lain tentang Letnan Komarudin, sehingga menjadi artikulasi eforia pelecehan metodologis penciptaan sumber belajar sejarah.

Eforia pencampuran yang dimaknai sebagai pelecehan metodologis juga muncul dengan penggabungan dokumentasi asli sejarah dengan dokumentasi dari aktivitas reenactor. Hal ini muncul dalam contoh Gambar 4. Terdapat konten yang membahas sosok Letnan Komarudin. Konten produksi AVID TEO itu memakai ilustrasi visual sosok asli Letnan Komarudin berdasarkan dokumentasi sejarah yang berwarna hitam putih. Pada foto itu digambarkan sedang berjabat tangan dan akan dipeluk oleh Jenderal Sudirman. Foto itu merupakan visualisasi figur asli Letnan Komarudin yang terdokumentasikan sejarah, namun dicampurkan dengan dokumentasi reenactor pada peringatan Serangan Oemoem tahun 2015. Di gambar tengah terdapat visualisasi beberapa reenactor mengacungkan senjata yang disatukan dalam satu frame dengan sosok Letnan Komarudin yang mengenakan baret merah, lalu beberapa wajah para pemain film Janur Kuning ditampilkan sebagai latar belakangnya. Sedangkan gambar paling kanan adalah kelompok reenactor dari Roodebrug Surabaya sedang beraksi dengan senapan replika, dengan keterangan tulisan 'Kisah Letnan Komarudin pahlawan yang akhirnya menjadi preman'.

Walaupun sebagai ilustrasi visual, kedua gambar itu masih punya benang merah yakni sebagai ilustrasi visual tentang 
peristiwa Serangan Oemoem Yogyakarta, namun sebagai konten sumber belajar sejarah, visualitas itu menjadi sesuatu yang membingungkan. Menjadi sumber belajar yang kurang berkualitas karena mencampuradukkan visualitas perang-perangan reenactor dengan kisah Letnan yang akhirnya menjadi preman. Dua subjek yang mencoba disatukan tanpa objektivitas yang jelas. Menjadi semacam kitsch dalam konten tentang Serangan Oemoem 1 Maret 1949, sebab memungut sisa-sisa dari hal yang telah terekspose habis-habisan.

\section{Retrogresif: repetisi otentisitas yang ambivalen.}

Reenactor melakukan aktivitas pengulangan sejarah pertempuran dengan kostum dan perlengkapan seotentik mungkin melalui aksi drama teatrikal peringatan pertempuran. Itu menjadi hobby sekaligus diklaim sebagai bentuk pembelajaran sejarah pertempuran. Sebagai ungkapan pelestarian sikap nasionalisme dan patriotisme dengan cara yang menyenangkan. Eforia itu menciptakan aneka dokumentasi visual yang dengan teknologi pengolahan digital image memungkinkan dapat dengan mudah direkayasa sedemikian rupa sehingga terkesan sebagai dokumentasi peristiwa pertempuran bersejarah, karena dokumentasi itu berubah menjadi wujud dramatisasi visual yang mampu menciptakan kesan faktual dan otentik, terutama bagi khalayak awam yang tidak dengan mudah membedakannya.

Sementara itu, salah satu upaya yang dilakukan dalam menghasilkan konten pembelajaran sejarah yang mendongkrak daya tarik adalah menggunakan ilustrasi visual. Namun penciptaan ilustrasi visual tidak semudah pembuatan ilustrasi verbal berbentuk tulisan. Penciptaan ilustrasi visual membutuhkan cara dan teknik-teknik dan proses yang lebih panjang dan lebih sulit. Namun karena memiliki kekuatan daya tarik yang luar biasa dan mendukung sifat media sosial yang sangat merayakan visual, maka kreator konten melakukan segala upaya untuk memasukkan unsur visual yang dominan. Cara yang paling mudah adalah mengambil gambar dari data visual yang telah tersedia, yakni berbentuk foto dan film dokumentasi tentang perang yang banyak terdapat di dunia maya. Termasuk aneka dokumentasi visual hasil aktivitas para reenactor. Itu digunakan menjadi ilustrasi visual perang yang mendukung konten pembelajaran sejarah yang akan diciptakan.

Banyak ilustrasi visual yang mengambil gambar atau scene-scene dari dokumentasi visual yang diambil serampangan, asal comot tanpa proses seleksi dan kurasi yang baik, misalnya terkait otentisitas. Hasil visual yang tidak berkualitas itu akan menghasilkan kekaburan ilustratif dan sangat besar menciptakan kondisi ambivalensi, atau kebingungan-kebingungan. Kebingungan visual, kebingungan objektivitas, bahkan kebingungan pembelajaran. Suatu bentuk pembelajaran yang membingungkan karena pencampuradukan rekasaya

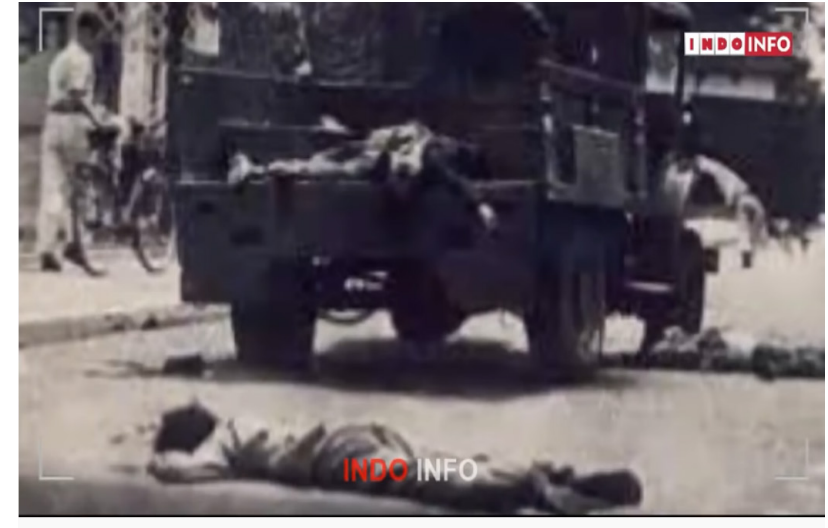

Kisah TNI Kebal Peluru, Kehebatan Letnan Komarudin Pada Serangan Umum 1 Maret

Gambar 5. Visual percampuran ilustrasi yang mengabaikan otensititas akibat kekacauan timeframe, kesalahan konteks dan ketidaknyambungan antara narasi dengan ilustrasi visual.

(Sumber: tangkapan gambar dari Youtube, 2021)

dan otentisitas, antara peristiwa sejarah dengan citraan dan simulakra. Konten yang mengedepankan emosi daripada logika kebenaran. Ilustrasi visual yang kabur dan miskin otentisitas, ilustrasi visual hasil rekayasa yang diulangulang untuk kepentingan yang berbeda sebagai penegasan atas narasi dan (ini yang memprihatinkan) demi konten. Demi popularitas follower atau jumlah like serta subscribe. Hal ini dimaknai berpotensi sebagai bentuk representasi pasca kebenaran (post truth) karena beroperasi sebagai kesesatan dalam pembelajaran sejarah. Sejarah yang semestinya mengutamakan realitas objektif. Pembelajaran sejarah ala pasca kebenaran otentisitas kebenaran sejarah justeru dikesampingkan. Penggunaan dokumentasi riil sejarah justeru ditinggalkan. Sejarah pasca kebenaran non-otentik yang terus digaungkan sehingga menjadi dianggap otentik. Suatu bentuk kekacauan realitas sejarah. Dalam Gambar 3 terdapat contoh yang kontras penggunaan ilustrasi visual otentik, analisa para sejarawan yang kompeten, saksi mata dan mengedepankan aspek metodologis. Namun disatukan dengan ilustrasi visual non-otentik menggunakan cuplikan adegan film komersil. Namun di Gambar 4, menampilkan apa yang dimaknai sebagai retrogresif ketika pengulangan kembali dilakukan dengan mengabaikan metodologis kontekstual sehingga konten menjadi kurang layak sebagai sumber belajar sejarah.

Fenomena yang makin menunjukkan makna retrogresif terdapat pada petikan gambar dari video unggahan INDOINFO di Youtube yang terdapat pada Gambar 5. Disana terdapat dokumentasi yang memperlihatkan beberapa mayat korban pemberontakan APPRA Bandung dengan teks Letnan Komarudin yang kebal peluru. Foto ini tidak sesuai dengan konteks peristiwa dan time frame, sebab menggunakan kalimat yang masih berkaitan dengan Letnan Komarudin, namun ilustrasi visual berasal dari foto dokumentasi sejarah peristiwa Pemberontakan Angkatan Perang Ratu Adil (APRA) pimpinan Westerling yang salah 
satunya terjadi di Bandung pada 23 Januari 1950.

Nampaknya kreator konten mengabaikan hal tersebut. Sebagai penciptaan media sumber belajar sejarah, konten itu menjadi sesuatu yang mengabaikan otentisitas dan berpotensi menciptakan kebingungan. Menjadi sesuatu yang justeru mengacaukan sejarah. Meskipun terdapat penggunaan dokumentasi riil sejarah, namun serta merta tidak menjadikannya konten pembelajaran sejarah yang baik dan bertanggung-jawab, sebab ilustrasinya tidak nyambung antara verbal dan visual. Konten yang hanya sekedar menimbulkan perhatian dan daya tarik mempertontonkan kesadisan. Namun menjadi sumber belajar yang tidak otentik terkait Letnan Komarudin yang kebal peluru. Itu menjadi sesuatu yang sangat ironis, sebab dengan teknologi internet pada jaman ini, sangat gampang mencari dokumentasi yang otentik kontekstual pendukung akurasi narasi.

Gambar 3a,3b, 4 dan 5 adalah objek material yang mempertontonkan kualitas sumber belajar yang tidak berkualitas, menjadi ungkapan bentuk ambivalensi visual yang terbentuk dari ilustrasi visual yang dicomot dengan paksa dan dikeluarkan dari konteksnya untuk kemudian digunakan lagi menjadi ilustrasi bagi narasi lain yang semakin meninggalkan konteksnya. Ilustrasi visual kesejarahan dianggap sebagai objek yang tidak bertuan dan outlaw. Dokumentasi yang dianggap milik sang pengarang yang telah wafat, sebagaimana diktum Barthes, the death of the author. Sangat kontras dengan jiwa dan semangat kesejarahan yang justeru menggali kebenaran dengan mengedepankan sumber-sumber data yang akurat. Konten kesejarahan yang menggunakan ilustrasi visual asal comot serta mengabaikan metodologis objektif tersebut berpeluang menciptakan ambivalensi. Suatu kondisi yang memunculkan sifat percabangan dua hal yang saling bertentangan. Ambivalensi dalam ilustrasi visual yang demikian itu memunculkan kondisi sejarah yang sejatinya non-sejarah terhadap objek kesejarahan. Sejarah menjadi objek yang berupaya menggali kebenaran objektif namun juga sejarah yang berpeluang memaparkan kebohongan melalui penggunaan artefak-artefak yang dicabut dari konteks dan otentisitas sejarahnya. Peristiwa sejarah yang dipaparkan ulang tidak lagi menjadi suatu tinjauan retrospektif yakni semangat menggali dan mencari kebaikan menuju pada sisi positif dan kemaslahatan kehidupan, namun bersifat retrogresif yakni meninjau ulang untuk menghasilkan kemunduran.

Sejarah memang milik pemenang. Itu menjadi diktum yang bisa ditawar, khususnya pada kehidupan kontemporer dimana banyak hal terdekonstruksi. Pemenang bukan lagi dalam peperangan fisik. Pemenang adalah yang menguasai media, mempunyai akses dan kapabilitas penciptaan konten. Pemenang juga adalah kreator konten yang mengedepankan penciptaan visualitas populer yang menarik perhatian, menciptakan banyak like dan subscribe agar alternatif sumber belajar sejarah sebagai agenda media juga menjadi agenda khalayak. Menciptakan simbiose yang menguntungkan sebagai komoditas ekonomi, menjadi artikulasi hidden message namun merugikan secara kualifikasi konten sebagai sumber belajar sejarah.

\section{SIMPULAN.}

Reenactor berkostum, berimpresi dan melakukan aksi teatrikal dalam peringatan peperangan bersejarah sebagai aktivitas menyenangkan hati sekaligus eforia cara dan media baru belajar sejarah pertempuran. Dokumentasi tentang aktivitas itu tidak sekedar sebagai dokumentasi peringatan pertempuran, namun jika tidak disikapi dengan bijaksana eforia itu berpotensi menghasilkan rekayasa visual. Apalagi teknologi pengolah digital sudah sedemikian canggih menghasilkan berbagai citraan dan simulasi. Dokumentasi yang dipakai sebagai ilustrasi visual tentang sejarah peperangan di media Youtube berpeluang menjadi subjek artikulatif populer yang tidak lagi independen. Sejarah ditulis oleh sang pemenang, bukan hanya pemenang perang, namun juga pemenang yang bahkan tidak terlibat dalam perang, pemenang dalam hal memperoleh akses media, menciptakan konten, kebebasan mengunggah konten dan mengekspresikan hidden agenda.

Peperangan pada jaman kini adalah perang proxy, suatu model peperangan yang tidak lagi menampakkan lawan dan kawan, bukan dengan desingan peluru atau ledakan bom. Perang proxy tidak melalui kekuatan militer, tak terbatasi secara geografis, perang melalui berbagai aspek kehidupan berbangsa dan bernegara. Bisa melalui politik, ekonomi, sosial budaya termasuk konstruk-konstruk sejarah. Konten sejarah di Youtube menjadi ungkapan pembelajaran sejarah yang anything it goes, karena tidak lagi mengedepankan otentisitas namun demi kepentingan kreator konten. Menjadi ungkapan kebebasan aktivitas reenactor dalam orientasi pembelajaran sejarah, padahal seyogianya belajar sejarah adalah juga memunculkan sikap kritis atas berbagai artikulasi dan kepentingan di dalam konten sejarah. Belajar sejarah adalah juga terwujudnya sikap selektif dan kritis-adaptif atas aneka kreativitas medium dan cara pembelajaran sejarah yang berkembang dinamis mengambil berbagai bentuk medium dan jalan masuk dari sesuatu yang tidak terbayangkan sebelumnya. Optimalisasi visualitas pada sumber belajar dipakai sebagai modus agar lebih interaktif dan menarik perhatian, namun seyogianya juga memberi ruang pada paparan verbal dan khalayak konten juga harus memahami konteks antara ilustrasi verbal dan visual yang disampaikan. Penyusunan materi sebagai konten sumber belajar sejarah juga harus melakukan trianggulasi sumber supaya objektivitas optimal. Belajar sejarah tidak boleh hanya membatasi pada satu paparan, harus menyediakan peluang tabayyun agar lebih objektif dalam melihat peristiwa pertempuran. Artinya harus juga memberi ruang yang adil 
dan sikap terbuka atas narasi yang muncul dari pihakpihak yang bertikai. Bahagianya para reenactor Indonesia, dengan setia menjadi penjaga otentisitas sejarah perang kemerdekaan, sambil menyuarakan sikap kritis non kompromis dan bersenang-senang dengan eforia kostum impresian serdadu jaman perang.

\section{DAFTAR RUJUKAN}

Dikovitskaya, Margaret. (2006). Visual Culture: The Study of the Visual After the Cultural Turn. Cambridge, MA: MIT Press.

Hagijanto, Andrian. (2017) Reenactoran Parodi Visual Karakteristik Serdadu KNIL Andjing NICA, Desertasi Pengkajian Senirupa, Pascasarjana ISI Yogyakarta.

Mirzoeff, Nicholas. (2009) What Is Visual Culture, Routledge, New York.

Routledge, New York . (2005) An Introduction to Visual Culture,

Rampley, Matthew.(2007) Exploring Visual Culture: Definitions, Concepts, Contexts, Edinburgh University Press.

Rose, Gillian. (2003) Visual Methodologies, Sage Publications, London.

Barnard, Malcom. (1996) Fashion Sebagai Komunikasi, Cara Mengkomunikasikan Identitas Sosial, Seksual, Kelas dan Gender, (Terj. Idi Subandy Ibrahim), P e n e r b i t Jalasutra, Yogyakarta.

Strinati, Dominic.(1995) An Introduction to Theories of Popular Culture, Routledge, London.

Sturken\&Cartwright. (2004) Practices of Looking : An Introduction to Visual Culture, Oxford University Press, London. 